\title{
Amid Rising Health Concerns in Hong Kong, Restaurants have Begun to Incorporate Traditional Chinese Medicine $\&$ Nutrition and Dietetics Knowledge into Recipe and Menu Development
}

\author{
Baldwin $\mathbf{W}^{*}$ \\ School of Hotel and Tourism Management, Hong Kong \\ Polytechnic University, Hong Kong \\ *Corresponding author: Baldwin W, School of Hotel \\ and Tourism Management, Hong Kong Polytechnic \\ University, 7F RM 711 East TST Kowloon, Hong Kong
}

Received: April 06, 2017; Accepted: May 25, 2017; Published: June 01, 2017

\begin{abstract}
The recent rise in food consumption related diseases has brought a higher level of awareness to both Hong Kong's government and its local population. While much of the burden for food consumption rests with the consumer, restaurants can also take steps to contribute, educate and guide diners to make healthier food consumption decisions. Several restaurants in Hong Kong are incorporating traditional Chinese Medicine philosophy and Western nutrition and dietetics information into their recipe and menu development process in an effort to provide a more nutritiously sound dining experience.
\end{abstract}

Keywords: Hong Kong; Nutrition; Traditional Chinese medicine; Restaurant; Health

\section{Introduction}

\section{Rising health concerns and daily recommended intake issues}

Hong Kong is becoming a beacon for culinary splendor in Asia. Most recently there have been several healthy, "green", sustainable and nutrition based eating trends that have taken the city's restaurant industry by storm [1]. This is a welcome change for the restaurant community in Hong Kong as both the consumer and the government have set forth their own initiatives to get local Hong Kong people to make healthier food decisions in their daily life $[2,3]$. The Hong Kong dietitians association's recommended consumption values and food pyramid have set guidelines for consumer intake with regards all major food groups with a large focus on grains, fruits and vegetables. And recently Hong Kong's Department of Health has put forth a series of recommendations for prevention and control based on the influx of non-communicable food related diseases. The study found that of the 4 behavioral risk factors analyzed, (smoking 15.9\%, low physical activity $18.9 \%$, binge drinking $8.9 \%$ inadequate fruit and vegetable intake) inadequate daily fruit and vegetable intake was the highest overall at $81 \%$ citing that there needs to be a change in the local consumption of fruit and vegetables to meet adequate overall intake. The study also showed that there the has been a significant increase in deaths due to diseases of the circulatory system, from $14.7 \%$ in 1996 to $25.9 \%$ in 2006 , and in cancer related deaths at $17.4 \%$ and $32.3 \%$ respectively [4].

Coinciding with this study, there was another study performed that analyzed the nutritional content of Chinese Dim Sum [5]. The study examined this common breakfast and lunch food of Hong Kong people by analyzing 71 different types of dim sum along with three common sauces used for boiled vegetables. Thorough chemical analyses were performed to measure the nutrient content of carbohydrates, protein, total fat, saturated fat, cholesterol, dietary fiber, sugar, sodium and calcium. The study found that while the steaming cooking technique was the most common means of cooking, some dim sum could still be high in fat, sodium and cholesterol while also being low in dietary fiber. In terms of healthy cooking approaches, steaming is traditionally seen as one of the healthiest non-fat cooking techniques [6]. The ratio and variance of the nutrients found in the dim sum depended on what type of dim sum was being made and consumed but one constant that was identified was very high amounts of sodium. Some soups and broths that were being prepared held as much as $1500 \mathrm{mg}$ of sodium per single serving. The overall implications of the study found that consumers must use caution with ordering and consuming dim sum for the fat, cholesterol and sodium contents; consume in Dim Sum moderate amounts and add non-sauced boiled vegetables to while dining to consume the Daily Recommended Intake (DRI) of dietary fiber from the meal. The previous studies help demonstrate the cause for more health conscious restaurants to have a positive impact in Hong Kong.

\section{Restaurants take the initiative for healthier dining options}

It is widely known that Hong Kong is one of Asia's centers for East meeting west, and from the East with regards to food there is a great influence from Traditional Chinese Medicine (TCM) in the food preparation approach in local restaurants. The examination of foods with cool and cold properties, warm and hot properties as well as medicinal foods and foods by taste can be food in various local Chinese restaurants in Hong Kong [7]. The approach of East meeting West has come to a place where traditionally Western vegan and vegetarian restaurants in Hong Kong are taking the subtexts of TCM and creating nutritionally based menu items by working with doctors and nutritionists within the Eastern and Western medicine disciplines. This conscious approach to recipe development and the preparation of healthier functional foods for consumers is a step in the right direction given the data collected from the Hong 
Kong government previous studies. In an attempt to help both the perception of the restaurant industry in Hong Kong and the consumer, several trending restaurants have taken heed to what has been presented about health risks and food consumption. Plantbased, organic and sustainable lifestyle restaurant models have been in an uptrend in Hong Kong for the last few years [8].

\section{The emergence of modern plant-based restaurants in Hong Kong}

Restaurants such as Life Café, Mana!, Sohofama, HOME Eat to Live and Grassroots Pantry have trail blazed the ideology of healthier food offerings for the local population. The former co-founder of Life Café and Mana! has taken the approach of the Middle Eastern food pyramid with their Lebanese and North African influenced plantbased menu offerings. The restriction of meat being served in their restaurant helps promote lower cholesterol and saturated fat intake while increasing plant-protein consumption in its place. Following the Middle Eastern food pyramid's reduction in dairy, egg and fish consumption while increasing whole grain, fruit and high-fiber vegetable intake helps the consumer make heart healthier choices [9]. HOME Eat to Live takes a similar model approach but is working with both local Hong Kong and American nutritionists in analyzing the calorie count and daily recommended intake of vegetables, grains and fruits per food item produced. HOME's raw and vegetarian approach to cuisine helps promote healthier cooking options and educates the consumer. The information is listed on the menu and within the menu item description for the consumer to read prior to making a choice of what to eat. Founder Christian Mongendre cites his inspiration for offering healthier plant-based food option stems from his parents' battles with cancer and how that related to their dietary intake. The input from the local and American nutritionists helps Christian and his team understands the dietary needs and perspectives of the local Hong Kong consumer and the large expatriate community that makes up his target demographic for the restaurant [10]. Restaurant Grassroots Pantry Chef Peggy Chan started her venture by wanting to offer healthy variations of comfort food while specializing in foods for people with dietary needs such as celiac disease, nut $\&$ dairy allergies, and various food intolerances [11]. Through vegan, vegetarian and raw food production, Grassroots' model focuses on maintaining the natural integrity of fruits, vegetables and grains to contribute a higher nutrient and nourishment value to her guests.

\section{Traditional Chinese medicine in recipe and menu development}

Taking a turn from plant-based cuisines, Sohofama's modern Chinese comfort food model has taken an incredible step-forward by partnering with both Eastern and Western Medicine practioners to develop recipes and flavor profiles that appeal to the unique palate and perceived taste of their guests. The chefs at Sohofama are trained in various forms of Chinese cuisine from Cantonese, Sichuan, Shanghainese and various others. They take their knowledge and flavor profile of those cuisines and use the TCM techniques and channel tropism to innovate dishes that are designed to help and heal the body. Once the recipe is in the developmental stage, the chefs prepare the dishes for the Eastern medicine doctors to evaluate and give input on what elements of TCM can be improved or added to the dish. An example would be their dim sum and soup offerings on their menu that incorporate elements of immunity enhancement, detoxification and boosting energy levels of the body and spirit. The focus on Chinese cuisine is different from the previous mentioned restaurants in that Sohofama still uses and serves a variety of animal products like chicken, beef and seafood. The meat and seafood products are all certified organic from various parts of the world but Sohofama goes further to examine hormone usage, intramuscular fat content and how the animals are raised when considering using them in the restaurant. Working with the Western doctors and nutritionists helps give the chefs insights in to how to control cholesterol levels of the animal products in their recipes and lowering levels of sodium in their soups, stocks and sauces made in-house. Founder Larry Tsang has said he just wanted people to know where their food comes from, what thought processes goes into making the food, and how the food that is prepared at Sohofama has been created with the local community's health and best interest in mind [12].

\section{References}

1. Fung C. Food trends Hong Kong. 2017.

2. USDA Foreign agricultural service GAIN report peoples Republic of China general rules for nutrition labeling of prepackaged foods Beijing. 2013.

3. Hong Kong dietitian's association department of health healthy eating food pyramid for adults. 2014.

4. Department of health Hong Kong promoting health in Hong Kong: A Strategy for prevention and controlling non-communicable diseases the government of Hong Kong special administrative region of China. 2014.

5. Food and Environmental Hygiene Department (FEHD) Nutrient values of Chinese dim sum. The government of the Hong Kong special administrative region of china. 2005 .

6. Culinary Institute of America. The Professional Chef New York: John Wiley and Sons. 2006.

7. Weng J, Chen J. The Eastern Perspective on Functional Foods Based on Traditional Chinese Medicine Nutrition Reviews Nov. 1996; 54: 11

8. Green Monday. Food trends to watch in 2017.

9. Babylon Restaurant Group Mana! 2017.

10. Mendoza. Christian J Mongendre is putting his passion for vegetarian living into his new Hong Kong venture HOME. 2017.

11. Grassroots Pantry Hong Kong. 2017.

12. Sohofama Hong Kong. 2017.
Austin J Nutri Food Sci - Volume 5 Issue 1 - 2017

ISSN : 2381-8980 | www.austinpublishing group.com

Baldwin. (C) All rights are reserved
Citation: Baldwin W. Amid Rising Health Concerns in Hong Kong, Restaurants have Begun to Incorporate Traditional Chinese Medicine \& Nutrition and Dietetics Knowledge into Recipe and Menu Development. Austin J Nutri Food Sci. 2017; 5(1): 1085. 